\title{
Physicians are not solely responsible for ensuring access to medical assistance in dying
}

\author{
Diane Kelsall MD MEd
}

Cite as: CMAJ 2018 February 20;190:E181. doi: 10.1503/cmaj.180153

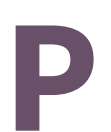
atients' rights to access to medical assistance in dying (MAiD) trumps the religious rights of physicians under the Canadian Charter of Rights and Freedoms - or so says the Ontario Superior Court of Justice. But ensuring equitable access to health care is a societal responsibility and does not rest solely on the individual physician. Surely there is a way forward that ensures access for patients requesting MAiD without trampling on physician rights enshrined in law.

On Jan. 31, 2018, the court upheld the College of Physicians and Surgeons of Ontario's regulations that physicians provide an "effective" or direct referral for MAiD. Several physician organizations had challenged two of the college's policies (Medical Assistance in Dying and Professional Obligations and Human Rights) on the grounds that they violated the charter. The court came down firmly on the side of patients' rights over physician rights. For many, this decision was a victory, reaffirming the centrality of the patient in our health care system. Yet the court agreed that these policies impeded the religious rights of physicians who object to providing referrals for MAiD.

When the federal legislation permitting MAiD came into effect on June 17, 2016, it did not address conscientious objection among health care providers. As seems to have become customary with contentious legislation, the federal government left the implementation details up to the provinces and their respective medical colleges.

For the most part, the Ontario college's relevant policies are rooted in the basics of physician professionalism. They call for doctors to act in a manner that respects patient dignity, communicating their objection to MAiD sensitively and not expressing "personal moral judgments." ${ }^{\text {As }}$ with any medical concerns, physicians must provide patients with information about available care and not withhold information about a procedure or treatment "because it conflicts with their conscience or religious beliefs."

Yet these policies move beyond physician professionalism with the requirement that doctors must refer patients requesting MAiD directly to "a non-objecting, available, and accessible physician, nurse practitioner or agency." In Nova Scotia, the provincial college has a similar policy. ${ }^{2}$

Failure to comply with these policies puts doctors at risk of discipline for unprofessional conduct, even though participating in MAiD would have been culpable homicide in this country until 2015. For physicians who object to MAiD on religious or other grounds of conscience, providing a direct referral makes them complicit in the procedure. This is not mere semantics - to be blunt, the physician must ask another health care provider to consider killing their patient.
In 2012, a CMAJ editorial cautioned that any change in Canadian law regarding euthanasia must safeguard both health care workers and patients from possible abuses in its application. ${ }^{3}$ Whereas patient safeguards are enshrined in the federal legislation, protections for physicians have been implemented inconsistently across the country. Some provinces have made strong provisions for conscientious objection. The College of Physicians and Surgeons of British Columbia's policy upholds the same tenets of professionalism as the Ontario and Nova Scotia colleges, but goes on to state explicitly that physicians are "not required to make a formal referral on behalf of the patient."

The responsibility to ensure access to MAiD does not rest with an individual physician, but with society. Recognizing this, most provinces have developed access programs for MAiD. The Ontario ministry of health has established a care coordination service where patients and caregivers can request directly to be connected to a doctor or nurse practitioner who provides MAiD. And yet, the provincial college still requires physicians to provide a direct referral.

When it comes to MAiD, balancing the rights of physicians and patients is not an easy task, but both deserve protection. Care coordination services for MAiD that are simple to access for self- or caregiver referrals should be available across the country. Physicians who are unwilling to provide a direct referral for MAiD should be prepared to provide patients and their caregivers with information about options that include such coordination services - but not required to provide a direct referral. And, of course, these discussions should always be rooted in professionalism and centred on the needs of the patient.

\section{References}

1. Medical assistance in dying. Policy statement no. 4-16. Toronto: The College of Physicians and Surgeons of Ontario; 2016 [updated July 2017]. Available: www.cpso.on. ca/Policies-Publications/Policy/Medical-Assistance-in-Dying (accessed 2018 Jan. 31).

2. Professional standard regarding medical assistance in dying. Halifax: College of Physicians \& Surgeons of Nova Scotia; 2017 Oct. 13. Available: https://cpsns.ns.ca/wp -content/uploads/2016/06/Medical-Assistance-in-Dying.pdf (accessed 2018 Jan. 31).

3. Flegel K, Fletcher J. Choosing when and how to die: Are we ready to perform therapeutic homicide? CMAJ 2012;184:1227.

4. Professional standards and guidelines - Medical assistance in dying. College of Physicians and Surgeons of British Columbia; 2016 June 23 (revised 2017 Apr. 28). Available: www.cpsbc.ca/files/pdf/PSG-Medical-Assistance-in-Dying.pdf (accessed 2018 Jan. 31).

Competing interests: See www.cmaj.ca/site/misc/cmaj_staff.xhtml

Affiliation: Editor-in-Chief (interim), CMAJ

Correspondence to: CMAJ editor, pubs@cmaj.ca 